HENDRICH, Yvonne: Brito, Cláudia - "Será que somos assim...

Para lá da tarefa: implicar os estudantes na aprendizagem de línguas estrangeiras no ensino superior.

Porto: FLUP, 2019, pp. 184-207

DOI: https://doi.org/10.21747/9789898969217/paraa10

\title{
"Será que somos assim?"1 - Análise contrastiva sobre a perceção do conceito de identidade portuguesa em aulas de Português Língua Estrangeira
}

\author{
Yvonne Hendrich \\ Johannes Gutenberg-Universität Mainz, Alemanha \\ hendric@uni-mainz.de \\ Cláudia Brito \\ Goethe-Universität Frankfurt, Alemanha \\ CorreiadeBrito@em.uni-frankfurt.de
}

\begin{abstract}
Resumo
Aprender uma língua estrangeira não deve visar apenas as habilidades linguísticas, mas também deve ajudar os aprendentes a tornarem-se cidadãos autónomos e responsáveis com competências interculturais. Enquanto público-alvo do variado material didático, é imprescendível envolver os alunos nas questões das representações da(s) cultura(s) associada(s) à língua meta, incentivá-los a dar opiniões críticas. Ao partilhar experiências em comum, como professoras de PLE na Alemanha, nas Universidades em Mainz e Frankfurt, este trabalho debruçar-se-á sobre a perceção que os alunos têm do conceito de identidade portuguesa e das respetivas imagens culturais, adquirida nas aulas de português através de materias didáticos diferentes. Visto que um grupo de estudantes trabalhara anteriormente com manuais de PLE e outro não e que ambos têm alemão como L1 ou L2, o texto que se segue pretende fazer uma análise contrastiva a partir de dados recolhidos através do preenchimento de inquéritos e de registos da execução de atividades efetuadas em aulas de PLE em ambas as universidades.
\end{abstract}

Palavras-chave: ensino de Português língua estrangeira, estereótipo, mediação cultural, material didático

\footnotetext{
${ }^{1}$ A citação "Será que somos assim?" provém do manual Aprender Português 3. Português para estrangeiros - Nível B2 (Oliveira \& Coelho, 2014, p. 70).
} 
HENDRICH, Yvonne: Brito, Cláudia - "Será que somos assim... Para lá da tarefa: implicar os estudantes na aprendizagem de línguas estrangeiras no ensino superior. Porto: FLUP, 2019, pp. 184-207 DOI: https://doi.org/10.21747/9789898969217/paraa10

\begin{abstract}
Learning a foreign language should not only aim at the linguistic skills, but should also help the learners to become autonomous and responsible citizens with intercultural competences. Being the intended consumers of diverse learning material, it is fundamental to involve the students in matters such as the cultural representation(s) associated to the target language, to encourage them to give their critical insights. By sharing our common ground as teachers of Portuguese as a foreign language in Germany, at the Universities of Mainz and Frankfurt, this article will address the perception of the students' concept of Portuguese identity and the respective cultural images acquired in the classroom by university students through varied learning material. As one group of students have worked with textbooks and another have not and both groups have German as L1 or L2, the following text intends to analyze by contrasting the data gathered by inquiries and their work during the classes of Portuguese in both universities.
\end{abstract}

Keywords: teaching Portuguese as a foreign language, stereotype, cultural mediation, didactic material

\title{
1 - Problematização sobre a utilização de manual enquanto
}

\section{ferramenta didática no ensino de Português Língua Estrangeira}

Utilizar um manual nas aulas de Português Língua Estrangeira ${ }^{2}$ ou não, eis a questão - pelo menos, é a questão central deste trabalho. Na sequência da nossa contribuição para o Colóquio Aprolínguas de 2016 (Hendrich \& Brito, 2018, p. 277-298), na qual já tínhamos abordado questões culturais relacionadas com o recurso, mais ou menos consciente, a estereótipos nos manuais de PLE, tínhamos concluído que se verificava "um discurso tendencialmente estereotipado nos textos apresentados nos manuais de PLE sobre assuntos de cultura, costumes e História" (Hendrich \& Brito, 2018, p. 295). Voltámos a participar novamente no colóquio em 2018 onde optámos por partilhar mutuamente as nossas experiências, enquanto professoras de PLE, nas Universidades de Mainz e de Frankfurt. O presente trabalho debruçar-se-á sobre a perceção que os alunos de PLE das universidades de Mainz e de Frankfurt, na Alemanha, têm do conceito de identidade portuguesa e das respetivas imagens culturais, adquirida nas

\footnotetext{
${ }^{2}$ A seguir, será aplicada a sigla PLE: Português Língua Estrangeira.
} 
HENDRICH, Yvonne: Brito, Cláudia - "Será que somos assim...

Para lá da tarefa: implicar os estudantes na aprendizagem de línguas estrangeiras no ensino superior.

Porto: FLUP, 2019, pp. 184-207

DOI: https://doi.org/10.21747/9789898969217/paraa10

aulas através de diversos materias didáticos. ${ }^{3}$ Visto que um grupo tinha trabalhado anteriormente com manuais de PLE e outro não e ambos os grupos têm alemão como L1 ou L2 ${ }^{4}$, o presente texto propõe uma análise contrastiva a partir de dados recolhidos através do preenchimento de inquéritos e de registos da execução de atividades efetuadas durante as aulas em ambas as universidades. ${ }^{5}$

Antes da análise dos dados dos inquéritos efetuados, convém fazer algumas reflexões liminares sobre a aquisição de competências interculturais no ensino de PLE e sobre o papel do manual (é necessário questionar o modo como este meio é frequentemente entendido como a ferramenta didática principal por professores e alunos em aulas de língua estrangeira). Segundo a definição apresentada no DecretoLei $n^{\circ} 369 / 90$, que estabeleceu o sistema de adoção, o período de vigência e o regime de controlo de qualidade dos manuais escolares, o manual serve como

instrumento de trabalho, impresso, estruturado e dirigido ao aluno, que visa contribuir para o desenvolvimento de capacidades, para a mudança de atitudes e para a aquisição dos conhecimento propostos nos programas em vigor, apresentando a informação básica correspondente às rubricas programáticas, podendo ainda conter elementos para o desenvolvimento de actividades de aplicação e avaliação da aprendizagem efectuada (Decreto-Lei n 369/90).

Manifesta-se, sem dúvida alguma, o papel importante "que o manual desempenha no processo de ensino-aprendizagem" (Guerreiro, 2012, p.13), visto que esta ferramenta de trabalho, em muitos casos, constitui um dos primeiros contactos que os aprendentes, em situação de aprendizagem de português como língua estrangeira, têm com a língua-alvo e a respetiva cultura. No ensino de PLE em instituições fora de Portugal, "é habitual o recurso a um manual como principal instrumento na sala de aula" (Hendrich \& Brito, 2018, p. 278), como é possível constatar através da lista de manuais adotados no ensino de português no estrangeiro, nomeadamente na Alemanha,

\footnotetext{
${ }^{3} \mathrm{Na}$ planificação desta análise contrastiva o nosso objetivo inicial era o estudo da perceção de identidades lusófonas pelos alunos de PLE. No entanto, por motivos que se prendem com a clareza de resultados e com a escassez de materiais sobre a lusofonia presentes nos manuais de norma europeia utilizados, decidimos cingir o estudo à perceção de uma identidade portuguesa. Porém, não excluimos a possibilidade de um futuro estudo que abranja identidades e culturas da lusofonia.

${ }^{4}$ L1: Estes aprendentes têm alemão enquanto língua nativa. L2: Estes utilizadores de alemão como língua segunda adquiriram-na durante a infância e utilizam-na no seu quotidiano (Cook, 2002, p. 1-8).

${ }^{5}$ Agradecemos imenso os alunos das aulas de PLE em Mainz e Frankfurt durante o semestre de verão de 2018 pela disponibilidade e pela participação nesse inquérito.
} 
HENDRICH, Yvonne: Brito, Cláudia - "Será que somos assim... Para lá da tarefa: implicar os estudantes na aprendizagem de línguas estrangeiras no ensino superior. Porto: FLUP, 2019, pp. 184-207 DOI: https://doi.org/10.21747/9789898969217/paraa10

publicada no site do Instituto Camões (Manuais escolares adotados, Alemanha, 2018/19), aplicável tanto ao ensino básico e secundário como ao superior.

Da perspetiva pedagógico-didática, segundo Guerreiro (2012, p. 14),

qualquer manual de LE deve constituir um auxílio, visando uma maior eficácia durante a aprendizagem, [...] possibilitando uma introdução progressiva dos conhecimentos necessários a adquirir ao longo da aprendizagem. [...] Enquanto veículo transmissor de conhecimentos, os manuais de LE devem incluir uma componente cultural.

Apesar de, neste contexto, nos parecer quase obsoleto repetir que a língua e a cultura se apresentam como elementos interligados e indissocáveis, e que aprender uma língua estrangeira não deveria apenas visar apenas as habilidades linguísticas mas também ajudar os aprendentes a tornarem-se cidadãos autónomos e responsáveis com competências interculturais, visamos dar expressão à definição das competências interculturais no âmbito do Quadro Europeu Comum de Referência para as Línguas:

O conhecimento, a consciência e a compreensão da relação [...] entre "o mundo de onde se vem" e "o mundo da comunidade-alvo" produzem uma tomada de consciência intercultural. É importante sublinhar que a tomada de consciência intercultural inclui a consciência da diversidade regional e social dos dois mundos. É enriquecida, também, pela consciência de que existe uma grande variedade de culturas para além das que são veiculadas pelas L1 e L2 do aprendente. Esta consciência alargada ajuda a colocar ambas as culturas em contexto. Para além do conhecimento objectivo, a consciência intercultural engloba uma consciência do modo como cada comunidade aparece na perspectiva do outro, muitas vezes na forma de estereótipos nacionais (Conselho da Europa, 2001, p. 150).

Com o objetivo de preparar os aprendentes de uma língua estrangeira para que sejam capazes de uma convivência imparcial e refletida, as competências interculturais procuram desenvolver as seguintes capacidades (Conselho da Europa, 2001, p.151):

- a capacidade para estabelecer uma relação entre a cultura de origem e a cultura estrangeira;

- a sensibilidade cultural e a capacidade para identificar e usar estratégias variadas para estabelecer o contacto com gentes de outras culturas; 
HENDRICH, Yvonne: Brito, Cláudia - "Será que somos assim... Para lá da tarefa: implicar os estudantes na aprendizagem de línguas estrangeiras no ensino superior. Porto: FLUP, 2019, pp. 184-207 DOI: https://doi.org/10.21747/9789898969217/paraa10

- a capacidade para desempenhar o papel de intermediário cultural entre a sua própria cultura e a cultura estrangeira e gerir eficazmente as situações de mal-entendidos e de conflitos interculturais;

- a capacidade para ultrapassar as relações estereotipadas.

Embora os manuais atuais de língua estrangeira estejam vinculados às diretivas do Quadro Europeu Comum de Referência para as Línguas (QECR) e inerentemente os seus autores assumam a responsabilidade de, nas propostas criadas, "ter atenção redobrada na selecção destes elementos e nunca descurarem o equilíbrio necessário aos mesmos, em função dos objectivos de aprendizagem, de forma a promover o desenvolvimento da competência cultural" (Araújo, 2010, p. 84), na nossa perspetiva assim como na opinião manifestada por aprendentes, como iremos analisar adiante, as imagens culturais são apresentadas de uma forma demasiado redutora, folclórica e estereotipada:

[...] na realidade, i. e., na prática, verifica-se frequentemente que os textos apresentados nos manuais de PLE abordam assuntos desatualizados com informações entretanto ultrapassadas, se afiguram inapropriados e com diálogos que soam artificiais e forçados [e] retratam Portugal de um modo demasiado simplista e limitado a estereótipos (Hendrich \& Brito, 2018, p. 282).

Neste contexto, a capacidade de intervenção e de pensamento crítico pelo professor torna-se fundamental, na medida em que este deverá assumir o papel de mediador (Grosso, 2006, p. 263) entre as ferramentas didáticas e o público-alvo com a compreensão da dimensão intercultural do ensino de uma língua estrangeira que por sua vez deve visar os seguintes objetos:

[...] to give learners intercultural competence as well as linguistic competence; to prepare them for interaction with people of other cultures; to enable them to understand and accept people from other cultures as individuals with other distinctive perspectives, values and behaviours; and to help them to see that such interaction is an enriching experience. [...] The role of the language teacher is therefore to develop skills, attitudes and awareness of values just as much as to develop a knowledge of a particular culture or country (Byram, Gribkova \& Starkey, 2002, p. 10, 13). 
HENDRICH, Yvonne: Brito, Cláudia - "Será que somos assim... Para lá da tarefa: implicar os estudantes na aprendizagem de línguas estrangeiras no ensino superior. Porto: FLUP, 2019, pp. 184-207 DOI: https://doi.org/10.21747/9789898969217/paraa10

O ensino de uma língua estrangeira "deve viabilizar o 'encontro' consciente com a 'Alteridade', sem comportamentos etnocêntricos que resultem em apreciações impressionistas negativas dos padrões culturais dos Outros, mas também sem autodesvalorização ou depreciação da pertença identitária de cada um" (Bizarro, 2012, p. 122). Deste modo é indispensável envolver os alunos, enquanto público-alvo do variado material didático, nas questões das representações culturais associadas à língua meta e incentivá-los a dar opiniões críticas e fazer sugestões construtivas.

\section{2 - Análise contrastiva entre duas universidades alemãs sobre a perceção do conceito de identidade portuguesa em aulas de Português Língua Estrangeira}

\section{1 - Descrição do questionário}

O despertar de consciências e sensibilidades para a interculturalidade foram o foco central dos inquéritos sugeridos aos alunos para a presente análise, assim como a sua capacidade de avaliação crítica quanto aos materiais didáticos que conhecem. Em relação à questão inicialmente colocada sobre o uso de manual ou não nas aulas de PLE, o inquérito procurou evidenciar a existência de diferenças (caso elas existam) na perceção e produções dos alunos através do contraste entre um grupo que tinha utilizado manuais e outro grupo que tinha utilizado material didático variado (criado ou selecionado de fontes diversificadas pela docente). Torna-se, por isso, relevante especificar que o corpus dos manuais de PLE que foram consultados pelo primeiro grupo é constituído pelos seguintes manuais: Português XXI 1 (A1), 2 (A2), 3 (B1) (Tavares, 2017) e Aprender Português 1 (A1/2), 2 (B1), 3 (B2) (Oliveira \& Coelho, 20142016), cuja primeira edição é de 2006-2007. Os exemplares consultados provêm das edições de 2014-2016. No caso dos manuais Português XXI, a primeira edição dos três volumes é de 2003-2005 e os exemplares consultados são de 2017. Quanto ao enquadramento, os dados foram recolhidos e tratados de forma anónima através de um questionário (modelo em anexo) em junho de 2018 pelas autoras do presente artigo, durante as aulas de PLE, nas universidades em Mainz e Frankfurt: Johannes Gutenberg-Universität Mainz e Goethe-Universität Frankfurt/Main. Como se pode verificar no modelo do questionário anexado, as perguntas abrangeram, resumidamente, assuntos referentes à história, cultura e identidade coletiva portuguesas, focando a questão central dos estereótipos. Os inquéritos foram disponibilizados a alunos de nível B1, que os preencheram voluntáriamente e em 
HENDRICH, Yvonne: Brito, Cláudia - "Será que somos assim...

Para lá da tarefa: implicar os estudantes na aprendizagem de línguas estrangeiras no ensino superior. Porto: FLUP, 2019, pp. 184-207

DOI: https://doi.org/10.21747/9789898969217/paraa10

anonimato. Em seguida, os dados destes inquéritos, para evidenciar com clareza o contraste, serão apresentados de forma alternada entre Mainz e Frankfurt. As respostas analisadas serão reproduzidas de forma original, i. e., incluindo gralhas e erros ortográficos.

\section{2 - Descrição dos informantes}

Os informantes constituem na sua totalidade estudantes de PLE com proficiência de língua avaliada nas respetivas instituições de ensino superior entre os níveis A2 e B2.

$\mathrm{Na}$ Universidade de Mainz, dez alunos (f: 5; m: 5) entre os 22 e 28 anos cuja L1 é o alemão, incluindo dois lusófono-descendentes (um descendente português, outra brasileira) responderam ao questionário. Como as áreas do bachelor major, os alunos inquiridos indicaram Estudos Românicos, Germanísticos, Anglofónicos, etc., Etnologia, Política, Pedagodia, História e Teologia. Os aprendentes estavam habituados a usar um manual de PLE, nomeadamente Português XXI, 1-3 (Tavares, 2017), nas aulas dos cursos de língua de português para, citando um dos alunos inquiridos, "aprender a gramática, ler e ouvir textos". O manual de PLE utilizado, nomeadamente os tomos Português $X X I, 1$-3 (Tavares, 2017), revelava um hábito enraizado ao longo dos anos, quer nos hábitos dos alunos, quer nos hábitos dos docentes. No caso dos alunos, a necessidade em recorrer a um manual poder-se-ia justificar com o facto de se sentirem mais confortáveis e mais confiantes ao ter um material físico e compacto em forma de livro ou caderno ao seu dispor que lhes permitisse acompanhar o processo estruturado das aulas, caso não pudessem estar presentes. Não obstante, parece relevante salientar que a docente, em complemento ao manual como suporte auxiliar nas aulas, disponibilizava materiais de apoio de variadas fontes (p. ex., fichas de trabalho e apresentações Powerpoint selecionadas e/ou criadas pela docente) numa plataforma online da universidade, o Reader, para que os alunos tivessem acesso a outros materiais variados (estruturas gramaticais, exercícios, vocabulário, etc.). Consciente da desatualização de certos conteúdos, assim como da falta de proximidade com o contexto real de comunicação, a docente também procurava demonstrar essas inadequações e desatualizações, tentando transmitir aos alunos para que utilizassem o manual de modo crítico.

Em Frankfurt, os oito participantes (f: $5 ; \mathrm{m}: 3$ ) seis deles tinham entre 21 e 26 anos e dois participantes tinham 58 e 67 anos. Seis dos alunos têm alemão como L1, um turco e outro espanhol e não há nenhum luso-descendente neste grupo. O leque das áreas de licenciatura e mestrado é similar às da universidade em Mainz e foi já referido 
HENDRICH, Yvonne: Brito, Cláudia - "Será que somos assim...

Para lá da tarefa: implicar os estudantes na aprendizagem de línguas estrangeiras no ensino superior. Porto: FLUP, 2019, pp. 184-207

DOI: https://doi.org/10.21747/9789898969217/paraa10

anteriormente. A diferença determinante do grupo de estudantes de PLE na universidade em Frankfurt consiste na não utilização de manual. Foram disponibilizadas aos estudantes através de plataformas cloud (OLAT e Google Drive) uma variedade de materiais e ferramentas de trabalho, alguns originais criados pela docente, outros provenientes de fontes diversificadas, selecionados pela mesma. O suporte deste material foi parcialmente imprimido pelos estudantes em papel e também consistiu, por meios digitais, em apresentações Powerpoint e jogos interativos originais assim como canções, reportagens e vídeos exibidos durante as unidades letivas através dos sítios de streaming Youtube e Vimeo.

\section{3 - Os estudos de português nas Universidades de Johannes Gutenberg (Mainz) e Goethe (Frankfurt)}

Para esclarecer as estuturas na Universidade Johannes Gutenberg, em Mainz, português como área de estudos faz parte do Departamento de Estudos das Línguas Românicas, na Faculdade de Filosofia e Filologia. O curso funciona como um Bachelor minor (Beifach), composto por sete módulos de diferentes áreas de estudo, composto pelas seguintes unidades curriculares obrigatórias: aprendizagem da língua (A1-B1), história, cultura, literatura, linguística, gramática, produção e expressão oral e escrita. Deste modo, no que diz respeito ao Bachelor major (Kernfach), i. e., área de estudos principal, dos respetivos alunos, observam-se as mais variadas áreas, como outras filologias ou ciências sociais (p. ex., filologias românicas e anglo-saxónicas, etnologia, história, ciências da educação, ciências políticas e comunicação). Além disso, os cursos de língua são de livre acesso a todos os estudantes e docentes da universidade que tenham interesse em aprender português e que queiram assistir à disciplina de forma voluntária por vários motivos (profissionais, académicos e familiares). Portanto, esta diversidade reflete-se num quadro bastante heterogéneo.

Quanto à Universidade Goethe, em Frankfurt, a oferta dos cursos de português enquanto língua estrangeira estão sob a orientação do Departamento de Línguas e Literaturas Românicas aos quais podem ter acesso estudantes de licenciatura ou mestrado. Além dos cursos de língua dos níveis $A 1, A 2, B 1$ e B2, há ainda a oferta de cursos de cultura histórico-social, expressão escrita, teatro, literatura, história da literatura e linguística. Como em Mainz, o grupo de alunos que participou no presente estudo contrastivo provém de variados campos académicos pela sua área de estudos principal (cinema, comunicação, ciências da educação, ciências políticas, etnologia, filologias românicas e anglo-saxónicas) que escolheram português como língua 
HENDRICH, Yvonne: Brito, Cláudia - "Será que somos assim... Para lá da tarefa: implicar os estudantes na aprendizagem de línguas estrangeiras no ensino superior. Porto: FLUP, 2019, pp. 184-207 DOI: https://doi.org/10.21747/9789898969217/paraa10

estrangeira de opção. Há ainda alguns participantes de Estudos Luso-Alemães para os quais os cursos de português são obrigatórios e que completarão mestrado nesta área com diploma duplo em parceria com a Faculdade de Letras da Universidade do Minho.

\section{4 - Resultados}

A primeira pergunta do questionário referia-se ao conhecimento da História de Portugal com o objetivo de apontar, do ponto de vista do informante, o acontecimento mais relevante da mesma. ${ }^{6}$ À primeira questão "Se tivesse de escolher o momento mais importante da História de Portugal, qual seria? Justifique a sua escolha.", o grupo de alunos da universidade em Mainz, que tinha tido contacto com manuais de português (nomeadamente com o manual Português XXI, 1-3 (Tavares, 2017), registou as respostas que se podem observar no gráfico da figura 1 que apresentamos a seguir:

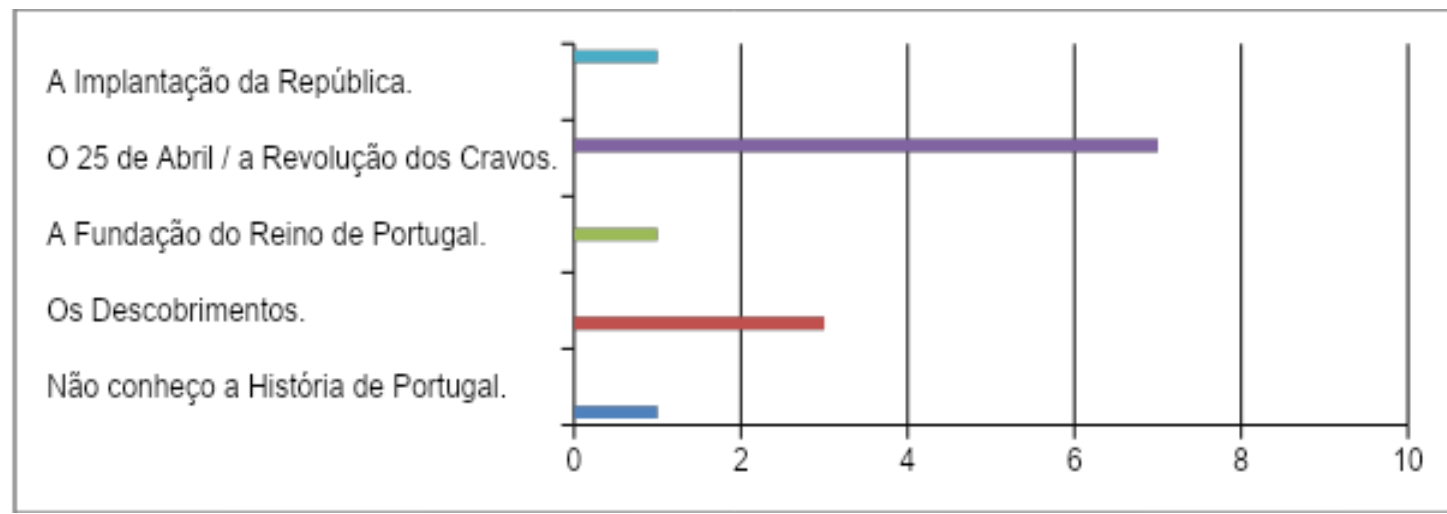

Figura 1. "Se tivesse de escolher o momento mais importante da História de Portugal, qual seria? Justifique a sua escolha.", respostas pelos inquiridos em Mainz.

Como justificações complementares, este grupo de estudantes indicou que "Com a fundação do Reino de Portugal começa tudo."; "Os Descobrimentos são a causa porque português é um dos idiomas mais falados no mundo.”, “[...] estabelecer uma democrácia é tão importante para todos os homens, portanto sempre tem de ser considerado muito relevante quando o estado democrático mais recente foi constituido.", "(o 25 de abril) Foi "o evento" da história resultante do movimento político e social. E também, o fim da ditadura de António de Oliveira Salazar." E finalmente "Porque este evento foi o primeiro passo para a democracia e, portanto, a fundação para o Portugal de hoje." Embora a Revolução dos Cravos seja, sem dúvida alguma, o momento mais marcante da história portuguesa contemporânea, não é abordada, incompreensivelmente, de nenhuma forma nos três tomos que fazem parte do manual Português XXI. Mesmo assim, sete

${ }^{6}$ Alguns inquiridos indicaram mais do que um acontecimento. 
HENDRICH, Yvonne: Brito, Cláudia - "Será que somos assim...

Para lá da tarefa: implicar os estudantes na aprendizagem de línguas estrangeiras no ensino superior. Porto: FLUP, 2019, pp. 184-207 DOI: https://doi.org/10.21747/9789898969217/paraa10

dos participantes de Mainz optaram pelo 25 de Abril de 1974. O conhecimento históricocultural dos alunos inquiridos deve-se particularmente ao facto de que quase todos frequentaram unidades curriculares sobre as culturas lusófonas com a mesma docente.

No gráfico seguinte podemos observar como, na universidade em Frankfurt, o grupo que não tinha sido exposto a manuais, respondeu à mesma questão:

A Adesão de Portugal à CEE.

O 25 de Abril / a Revolução dos Cravos.

A restauração da Independência.

Os Descobrimentos.

Não conheço a História de Portugal.

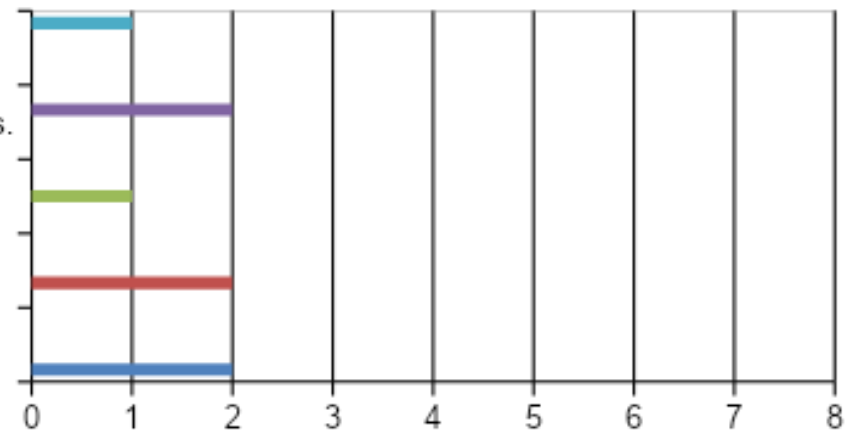

Figura 2. "Se tivesse de escolher o momento mais importante da História de Portugal, qual seria? Justifique a sua escolha.", respostas pelos inquiridos em Frankfurt.

Complementarmente, grupo de informantes comentou ainda "os Descobrimentos têm efeitos mais longe - até hoje."; "A restauração da Independência (1640), porque sem a Restauração, a língua dominante no Portugal e nos países portugueses poderia ser 0 espanhol."; "O 25 de Abril / a Revolução dos Cravos (1974), porque é a coisa mais atual e interessante." e "O 25 de Abril / a Revolução dos Cravos (1974), porque é um Wendepunkt* ("ponto decisivo) para a sociedade portuguêsa.". A este grupo de alunos tinham sido facilitadas algumas informações históricas, embora de forma dispersa, durante os diferentes níveis dos cursos de língua. No decorrente semestre foram abordados, especificamente, excertos do romance "O Retorno" de Dulce Maria Cardoso o que pode justificar as escolhas do 25 de abril como momento histórico decisivo português. No entanto, e tendo em conta que o tempo é escasso nestas aulas para a aquisição de conhecimentos aprofundados de História, justificam-se as restantes respostas também pelo contacto com textos e literatura em aulas de Cultura, História e Literatura Lusófonas.

No que diz respeito à pergunta "Que símbolos relaciona com Portugal?", obtivemos, conforme esperado, respostas bastante semelhantes nos dois grupos. Na universidade em Mainz, os estudantes apontaram o "fado"; a "saudade"; "CR7"; "mar e praias" ;"futebol"; "sardinhas"; "bacalhau”; "caravela"; "Torre de Belém"; "pasteis de nata"; "vinho do Porto"; "Algarve"; "galo de Barcelos"; "cravo" e "azulejos". Também o grupo de 
HENDRICH, Yvonne: Brito, Cláudia - "Será que somos assim... Para lá da tarefa: implicar os estudantes na aprendizagem de línguas estrangeiras no ensino superior. Porto: FLUP, 2019, pp. 184-207 DOI: https://doi.org/10.21747/9789898969217/paraa10

Frankfurt respondeu "alegria de viver"; "vinho"; "futebol”; "praia”; "fado"; "azulejos"; "CR7"; "caravela"; "queijo da Serra" e "Algarve".

$\mathrm{Na}$ questão que se segue, foi proposto aos alunos que expressassem de forma crítica a sua opinião sobre dois textos retirados do manual Aprender Português 3 (B2) (Oliveira \& Coelho, 2014) que retratavam uma suposta identidade portuguesa e passamos a citar:

Texto 1: Portugal, país com uma história feita de heróis, deu ao mundo novos mundos e, apesar de hoje em dia ser geograficamente menor do que era no passado, continua a ser o responsável pela grande influência que teve noutras terras, culturas e gentes. Durante a nossa viagem pela História, deixámos importantes raízes na Índia (Goa, Damão e Diu), em Timor, em África e no Brasil. Para conhecer Portugal, é preciso que você conheça o seu presente, mas também o seu passado. Conhecer Portugal é conhecer a alma do seu povo, as suas tradições, as suas festas, os seus usos e costumes. Conhecer Portugal é conhecer as pessoas que tornaram o país conhecido pelo mundo fora. Devido ao seu espírito aberto, os portugueses gostam que os estrangeiros visitem o seu país, conheçam a sua cultura, provem a sua comida. Se você conhece Portugal, ou se já o visitou, então sabe que os portugueses estão sempre prontos para ajudar um visitante em dificuldades. Os portugueses são amigos do seu amigo e esperam que os demais tenham o mesmo sentimento para com eles. Não é à toa que se diz "quem meu filho beija, minha boca adoça". Se você gostar do nosso "Portugalinho", então cairá nas boas graças dos portugueses. E, como "amigo verdadeiro vale mais do que o dinheiro", terá para sempre amigos fiéis e dedicados que Ihe pregarão dois beijinhos e muitos abraços como qualquer bom português (Oliveira \& Coelho, 2014, p. 28).

Texto 2: Caso os leitores decidam visitar Portugal, ficarão abismados com a simpatia do seu povo. Antes de chegar a Portugal, muitos estrangeiros imaginam que os portugueses são parecidos com os seus irmãos espanhóis, ou talvez com os seus primos italianos. Todos imaginam que os portugueses são vivos, alegres, exuberantes como os seus vizinhos latinos, mas, na realidade, os portugueses são mais calmos. Se decidir conviver com os portugueses, aprenda a ser como eles (Oliveira \& Coelho, 2014, p. 74).

Em Mainz os alunos reagiram com respostas como "Eu acho que o primeiro texto mostra muito dos pensamentos antigos que os portugueses tem. Que Portugal é um país grande etc. Creio que ainda tem muitos que pensam assim. E Também acho que realmente os portugueses sao mais calmos que a espanhois ou italianos (texto 2)."; "São estereotipados, generalização da população, exageros."; "Como muitas pessoas não 
HENDRICH, Yvonne: Brito, Cláudia - "Será que somos assim... Para lá da tarefa: implicar os estudantes na aprendizagem de línguas estrangeiras no ensino superior. Porto: FLUP, 2019, pp. 184-207 DOI: https://doi.org/10.21747/9789898969217/paraa10

têm noção do povo português é provavelmente certo que as pessoas comparam do povo português com os seus vizinhos latinos. Por isso pode o texto 2 ser considerado como a imagem estereotipada, enquanto o texto 1 representa a realidade. Esta realidade só podem reconhecer as pessoas que têm experiência com a cultura portuguesa."; "Texto 1) Claro a realidade. Portugal têm uma história gloriosa. Mas o texto esquece o período colonial. O resto o texto parecer familiar para mim. Os portugueses são adoráveis e abertos. E eles adoram o país deles. Texto 2) Na minha opinião, neste texto têm aspetos de estereotípicos e da realidade. Minha companheira de casa já disse: Os portugueses são como os espanhóis e os latinos. Mas agora, depois meu tempo ali, eu acho que os portugueses são mais calmos. Um pouco."; "O primeiro texto parece um pouco exagerado. O que significa 'a alma do seu povo'? Tem um povo uma alma junta? Não estou com certeza. Mas também está verdadeira, conhecer um país é conhecer costumes, tradições... Além disso acho que Portugal deveria tentar se definir sem sempre lembrar o grande imperio, porque sonhar do passado só pode ser um parte da concepção de si mesmo. O segundo texte diz que toda pessoa quem conheço me disse depois ela foi em Portugal a primeira vez. Então acho que não pode ser totalmente falso."; "Texto 1) É verdade que o Portugal tem uma história interessante e uma cultura muito rica com suas tradicões, suas festas e sua comida, mas acho que este texto é um poquinho exagerado, se o Portugal fosse o melhor pais do mundo. Texto 2) Este texto é mais neutro. Na verdade quando estive no Portugal, me parece que portugueses tambén são muito alegres e vivos. Eles não são nada calmos."; "Ambos os textos têm aspectos verdadeiros. Especialmente o segundo texto acho muito apropriado. Durante o meu semestre em Lisboa, percebi os portugueses como pessoas tranquilas mas mas muito amigáveis. Eu também achei os portugueses muito tradicionais."

Em resumo, destacam-se as respostas críticas no que diz respeito à suposta glorificação da História Portuguesa no texto 1. Uma vez que - como já foi referido - os manuais utilizados lamentavelmente não abordam esse assuntos de forma adequada ou satisfatória, o conhecimento de aspetos histórico-culturais e a capacidade de desenvolver uma opinião crítica depende do input de informações suplementares mais abrangentes por parte da docente para estimular o interesse a e consciência dos alunos.

Já o grupo de alunos que não tivera contacto com manuais de PLE, ofereceu respostas que também demonstram o sentido crítico destes leitores e que denunciam os estereótipos, como em "Acho que os dois textos tem muitos estereótipos. Se quer vender uma imagem agradavel para aumentar o turismo em Portugal. Os turistas 
HENDRICH, Yvonne: Brito, Cláudia - "Será que somos assim...

Para lá da tarefa: implicar os estudantes na aprendizagem de línguas estrangeiras no ensino superior.

Porto: FLUP, 2019, pp. 184-207

DOI: https://doi.org/10.21747/9789898969217/paraa10

precisan de conhecer o país e a sua gente sem ideias e imagems estereotipadas. Mais estou seguro que os portugueses são em realidade gente muito boa. só acho que é compicado geralizar adjetivos para uma região tão grande como é Portugal. Os estereótipos reforçam nacionalismos e problemas culturais / etnicos."; "Acho que os dois textos correspondem à realidade mas também são esterotipados. Cada pessoa que vai para Portugal vai ter a imagem do promeiro texto mas vai descobrir que as características do segundo texto são mesmo típicas quando se aproxima dos portugueses." Três inquiridos destacaram ainda o primeiro texto apresentado, como o mais estereotipado como se pode ler em "Acho que o primeiro texto é mais estereotipado do que o segundo.”; "O primeiro texto é muito estereotipado. Quer fazer publicidade para o Portugal. O texto 2 é provávelmente mais realistia. "Houve ainda um estudante que condenou a conotação política de pendôr nacionalista do primeiro texto: "Acho que o primeiro texto é muito estereotipado e parece ser o prefaço de um livro de nacionalistas. O segundo texto de facto também fala em estereotipos mas num que é aplicado a um grupo: os latinos. Acho que é justificado falar em termos de mentalidades diferentes de vários povos para facilitar um concurso. Mas nunca se deve esquecer que qualquer grupo consiste em indivíduos. Em relação às minhas experiências posso concordar com a têse que os portugueses são mais calmos e até menos alegres, que os seus vizinhos.". Uma reposta apontou ainda o segundo texto negativamente estereotipado "Texto 1) Nunca foi para o Portugal, então é difícil para mim julgar isto. Porém, acho que o texto parece muito bom e me da vontade de conhecer a cultura portuguesa e o pais em geral. Texto 2) Este texto parece mais negativo, e não acho que é verdade. As pessoas portugueses que eu já conheci na minha vida sempre foram muito alegres e não muito calmas. Mas, eu acho também que são diferentes dos italianos ou espanhóis." Por último, houve ainda respostas com considerações sobre as diferenças entre o que é estereotipo ou realidade, como em "Penso que os dois textos correspondem à uma parte da realidade portuguesa. Todos as pessoas tem uma imagem das suas pais e também pensam que sabem como os estrangeiros viram o pais. Mas a realidade nunca é preto ou branco, sempre tem '50 shades of cinzento'."

A promoção da leitura crítica no ensino superior é uma qualidade essencial e deve estar no espírito de todos os estudantes universitários. No entanto, no caso de uma língua estrangeira e particularmente para aqueles que não têm qualquer referência externa, pode tornar-se difícil distinguir a realidade do estereótipo ou da propaganda. Cabe ao professor, ao facilitar materiais, expôr as variadas perspetivas e possibilidades de leitura e promover o debate em sala de aula. 
HENDRICH, Yvonne: Brito, Cláudia - "Será que somos assim...

Para lá da tarefa: implicar os estudantes na aprendizagem de línguas estrangeiras no ensino superior. Porto: FLUP, 2019, pp. 184-207 DOI: https://doi.org/10.21747/9789898969217/paraa10

À questão na segunda parte do questionário "Na sua opinião, é importante conhecer a cultura e a história de um país para aprender a respetiva língua? Justifique.", os alunos de Mainz concordaram todos com unanimidade acerca da interligação de cultura e língua. Eis as respetivas respostas: "Falar uma língua todo mundo pode, entender como falar com as pessoas do país, so vai conseguir se saber da história e da cultura."; "Acho que a língua sempre faz parte duma cultura, assim é importante aprender uma língua junto a cultura e história."; "Na minha opinião, é importante porque issos aspetos podem ser asuntos potenciais para falar com portugueses."; "Como 'a minha patria é a lingua portuguesa', É importante entender a cultura se você quer realmente entender a linguagem."; "Conhecer a cultura facilita aprender a lingua. Ao longo da história, uma língua como a língua portuguesa ganha das palavras e expressões das outras línguas e culturas, neste caso também da África e do Brasil. A cultura estampa a língua tendo a sua 'cara' nunca sem a cultura."

À mesma questão, no grupo de aprendentes de PLE em Frankfurt, seis responderam que é importante conhecer a cultura e a história de um país para aprender a respetiva língua com as justificações "Todas a épocas históricas marcan la língua de um país." e "A língua é fruto da cultura e da história de um povo.". Dois estudantes consideraram que os conhecimentos de história e cultura não são importantes para a aquisição de língua-meta justificando "Mas é interessante; "Não é preciso para conseguir. Mas pessoalmente é aconselhável."

Apesar destas duas últimas considerações, há uma opinião generalizada a favor desta interdisciplinaridade.

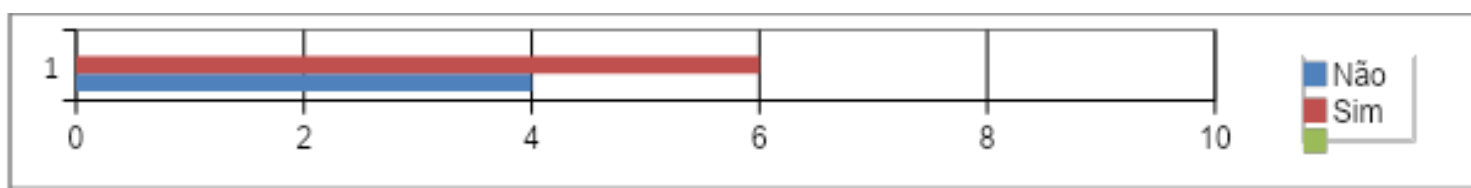

Figura 3. "Na sua opinião, os manuais que conhece abordam suficientemente temas de cultura portuguesa?", respostas pelos inquiridos em Mainz.

No gráfico anterior (Figura 3) estão representadas as respostas em Mainz à questão "Na sua opinião, os manuais que conhece abordam suficientemente temas de cultura portuguesa?". É compreensível os alunos considerarem, em geral, que os variados assuntos culturais são razaovelmente abordados nos manuais que conhecem, visto que, cada unidade trata de um aspeto cultural distinto como, p. ex., tradições, relações familiares, gastronomia, turismo, geografia e e-/imigração, entre outros, embora vários textos careçam de uma atualização. Não obstante, se a pergunta tivesse focado em "temas da história portuguesa", provavelmente mais inquiridos teriam discordado. Ainda 
HENDRICH, Yvonne: Brito, Cláudia - "Será que somos assim...

Para lá da tarefa: implicar os estudantes na aprendizagem de línguas estrangeiras no ensino superior. Porto: FLUP, 2019, pp. 184-207 DOI: https://doi.org/10.21747/9789898969217/paraa10

em Mainz, o mesmo grupo considera na totalidade (10 indivíduos) que "temas de cultura são suficientemente tratados nas aulas de PLE.": "Sim. Nas aulas da nossa professora [i. e., as aulas suplementares de cultura e história lusófonas da mesma professora]." e "Sim. No curso de línguas, eles são parcialmente tratados."

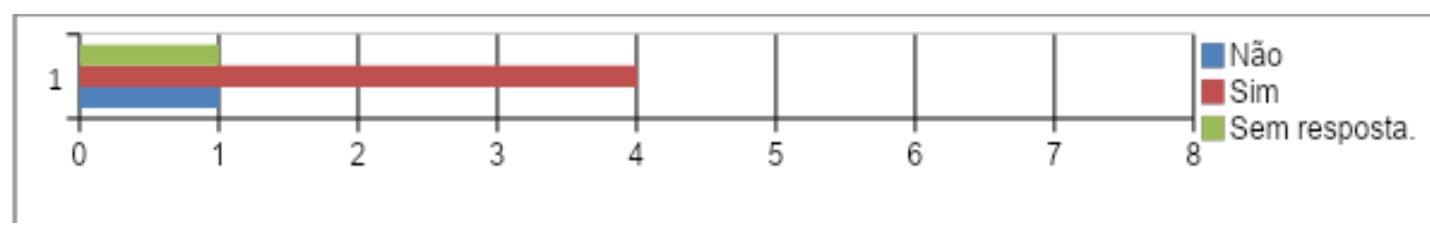

Figura 4. "Na sua opinião, os manuais que conhece abordam suficientemente temas de cultura portuguesa?", respostas pelos inquiridos em Frankfurt.

Já em Frankfurt foram registadas as respostas que podemos ver na figura 4. 0 informante que não responde justifica que "depende do nível". Apesar do grupo de alunos em Frankfurt não ter trabalhado com manuais de PLE na sala de aula, há estudantes que por opção pessoal adquiriram um para trabalhar de forma individual fora do horário curricular.

Eis as respostas, na figura 5, pelos informantes de Mainz, à pergunta "Considera que a informação que têm sobre Portugal corresponde à realidade ou é estereotipada?"

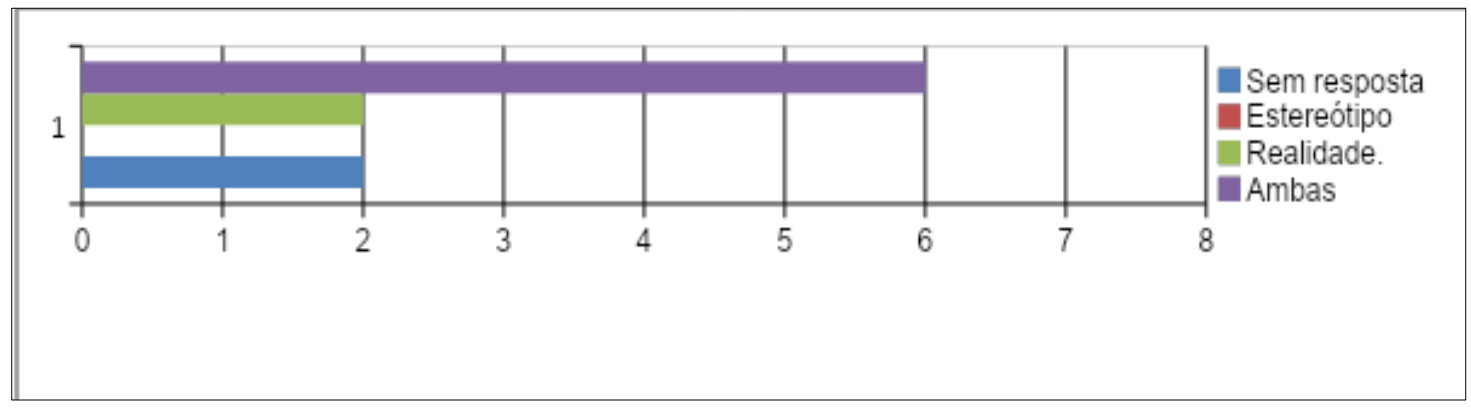

Figura 5. "Considera que a informação que têm sobre Portugal corresponde à realidade ou é estereotipada?", respostas pelos inquiridos em Mainz.

Este grupo de inquiridos justifica as respostas do seguinte modo: "Nunca fui a Portugal, assim não conheço a realidade."; "Quando visitei o país, reconheci muitas aquelas estereotipadas. Estive muito surpreso."; "Eu vivi em Portugal por cinco meses. Eu conheço bem os estereotípicos mas a realidade também um pouco."; "Estudei um semestre em Lisboa em 2018. Acho que os estereótipos são geralmente associados a um pouco de verdade, mas na maioria dos casos são exagerados."; "Quando falamos de um país sempre falaremos sobre estereotipos. Porque isso são as informações que a maioria tem e conhecem. Depois podemos pouco a pouco mostra o que é realidade e o que não é."; "Como já vivi em Portugal penso que a minha informação sobre Portugal 
HENDRICH, Yvonne: Brito, Cláudia - "Será que somos assim...

Para lá da tarefa: implicar os estudantes na aprendizagem de línguas estrangeiras no ensino superior.

Porto: FLUP, 2019, pp. 184-207

DOI: https://doi.org/10.21747/9789898969217/paraa10

corresponde à realidade.". Salienta-se que as respostas se baseiam, sobretudo, no facto de alguns dos inquiridos já terem estado em Portugal por razões académicas (ERASMUS) e/ou pessoais e, portanto, eles próprios terem tido a oportunidade de vivênciar a assim considerada "realidade" no quotidiano.

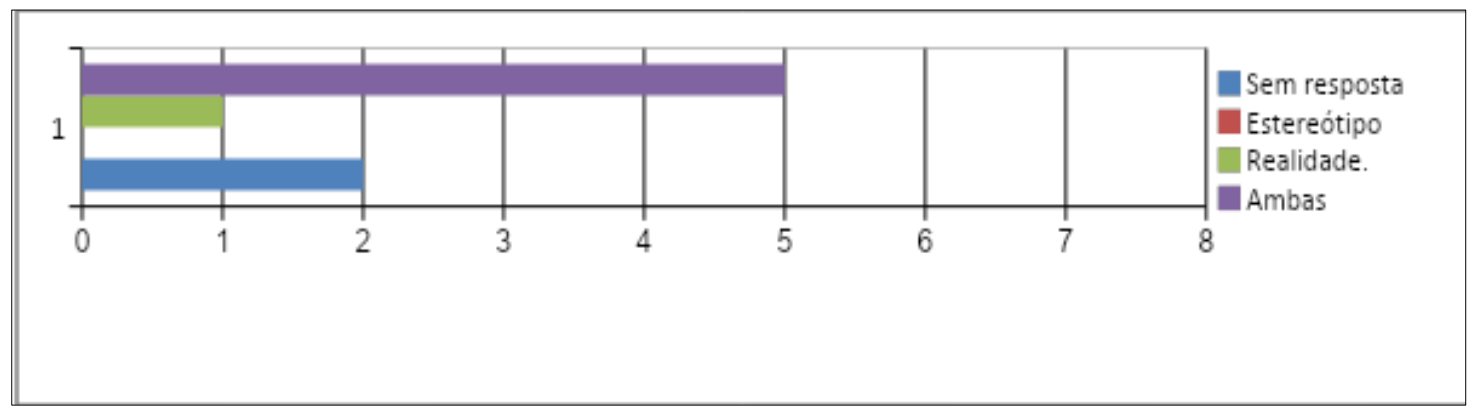

Figura 6. "Considera que a informação que têm sobre Portugal corresponde à realidade ou é estereotipada?", respostas pelos inquiridos em Frankfurt.

À mesma questão, os inquiridos em Frankfurt consideram na sua maioria (cinco) que a informação que têm sobre Portugal é ao mesmo tempo real e estereotipada e justificam as suas respostas dizendo "Ambos. Certamente não todas as informações são estereotipadas, mais por outro lado há definitivamente algumas coisas correspondem à verdade."; "Os dois, é sempre um bocadinho da realidade no estereótipo."; "Ambas. Eu acho que estereótipos são sempre um pouco demais, mas há coisas que têm tendências de ser verdades.". Há ainda um estudante que afirma "Realidade porque estive lá muitas vezes.

Quando confrontados com a última questão "Acha positivo e necessário fazer estereótipos culturais?", seis alunos em Mainz respondem que não e quatro respondem afirmativamente.

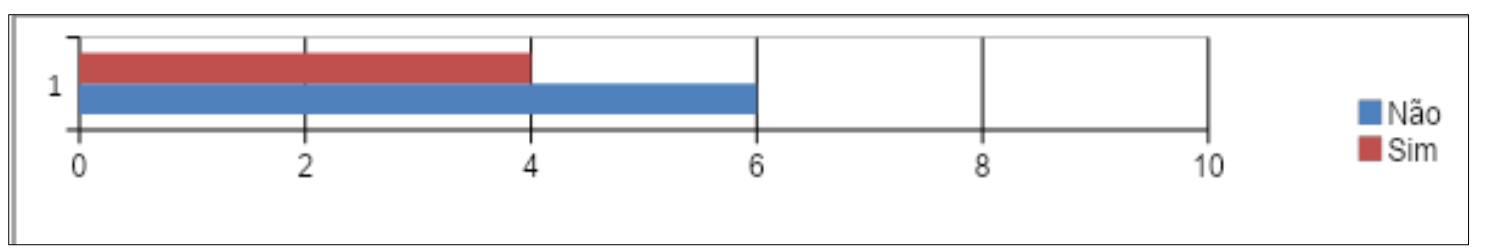

Figura 7. "Acha positivo e necessário fazer estereótipos culturais?", respostas pelos inquiridos em Mainz.

Os inquiridos justificam e especificam que, os estereótipos, embora tendam a retratar uma cultura de forma tendenciosa, possam ajudar a entender uma construção tão complexa como a cultura: "Não. Na minha opinião fazer estereótipos culturais é negativo, porque assim a imagem de uma pessoa sobre um país vai ser falsificado."; "Sim. Estereótipos geralmente ajudam a entender melhor a cultura do país."; "Sim. Com 
HENDRICH, Yvonne: Brito, Cláudia - "Será que somos assim... Para lá da tarefa: implicar os estudantes na aprendizagem de línguas estrangeiras no ensino superior. Porto: FLUP, 2019, pp. 184-207 DOI: https://doi.org/10.21747/9789898969217/paraa10

certeza. É normal. Todos os países têm estereotípicos culturais. Na Alemanha é a mulher com um 'Dirndl' ou um homem com o 'Lederhose'. Eu acho que nos precisamos deles para associar temas e motivos com um país."; "Sim. Não existe nenhuma pessoa que não pense em estereotipos especialmente quando se trata de algo que ela não conhece. Mais estereótipos ajudam a ter uma base que todos nos possa conversar. Só não pode guardar estereótipos como se fosse a única realidade."; "Sim. Os estereótipos podem apoiar a construição de um imagem 'romantica' que ajude uma pessoa que queira sentir-se bem pensando à um país como Portugal. Em geral se gostar 'sonhando' de uma cultura/nação com um imágem agrádavel."

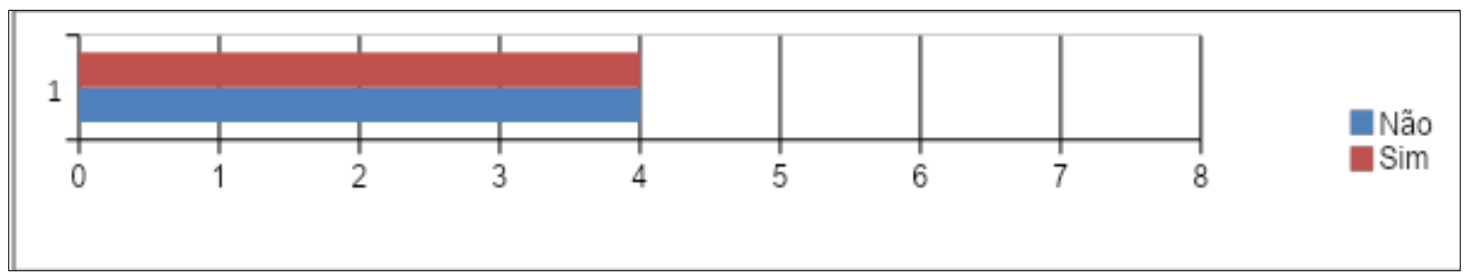

Figura 8. "Acha positivo e necessário fazer estereótipos culturais?", respostas pelos inquiridos em Frankfurt.

As opiniões dos estudantes em Frankfurt sobre esta questão dividem-se. Do lado defensor do recurso a esterótipos são apontados os argumentos como "Ajuda a entender uma coisa complexa."; "Porque dá uma ideia do país."; "Se uma pessoa pode rir disso, porque não?" e "Sim, porque os estereótipos simplificam o acesso à um pais.". Um dos inquiridos que respondeu negativamente acrescentou ainda que apesar de os estereótipos culturais não serem positivos estes se tornam "imprescindíveis".

\section{5 - Interpretação de dados}

Os dados obtidos apontam para a inexistência de disparidades que evidenciem respostas influenciadas pelo manual de PLE ou pela ausência do mesmo (apesar da urgência na criação de material mais adequado), o pensamento dos alunos não é muito diferente, p. ex., quanto às suas considerações sobre a necessidade de estereotipar para simplificar e apresentar a cultura, isto sem conotações negativas ou de propaganda nacionalista.

Ao voltar à problemática inicial sobre eventuais benefícios da utilização ou não de um manual, podemos concluir que, para os aprendentes, a proveniência do material didático em si - seja de um manual, seja material original - parece ter menos relevância do que o modo como estas ferramentas didáticas são trabalhadas pelo professor. Depende, principalmente, do professor incentivar o olhar crítico pelos alunos e exercer 
HENDRICH, Yvonne: Brito, Cláudia - "Será que somos assim... Para lá da tarefa: implicar os estudantes na aprendizagem de línguas estrangeiras no ensino superior. Porto: FLUP, 2019, pp. 184-207 DOI: https://doi.org/10.21747/9789898969217/paraa10

o papel de mediador entre ferramenta e alvo, embora seja inevitável uma certa subjetividade na seleção de materiais por parte do mesmo em relação àquilo a que se propõe tratar: seja através de um manual, seja através de material didático original.

\section{3 - Considerações finais}

É necessário trabalhar crítica e refletidamente, que significa, em concreto, questionar símbolos identitários e imagens estereotipadas para despertar consciência (auto)crítica e desenvolver competências interculturais. Para transmitir e discutir identidades nacionais de modo mais profundo, as aulas da aquisição de língua não são suficientes - constata-se que é desejável (ou melhor: indispensável) ofecerer informações ou até aulas suplementares sobre história, cultura, sociedade.

Quanto à elaboração e redação de manuais de ensino de PLE, manifesta-se o desideratum de uma premente necessidade de atualizar (preferencialmente de forma digitalizada) temas e tópicos, de abordar as culturas dos países de língua portuguesa além de Portugal - de forma mais abrangente e de evitar apresentações culturais e imagens identitárias demasiado redutoras e estereotipadas.

$\mathrm{Na}$ conclusão a esta análise contrastiva entre dois grupos com e sem acesso a manuais de PLE, o fator que revelou uma dimensão decisiva nos dados recolhidos foi o papel do professor, que ao trabalhar (muitas vezes por norma do estabelecimento de ensino onde leciona) com materiais e textos tendenciosos ou que reduzem as culturas e identidades de um povo ou país a estereótipos, tem o dever essencial de promover o pensamento crítico e sugerir a amplitude das variedades sejam elas linguísticas ou culturais e as diferentes perspetivas de que o mesmo tema pode ser alvo. Os estereótipos, enquanto reduções identitárias às vezes até (auto)irónicas e humorísticas, cumprem o seu papel quando são oferecidos aos aprendentes como tal e não como espelhos de realidade como é frequente encontrar hoje nos mais variados manuais de PLE.

Afinal, cabe a cada professor escolher e utilizar o material didático que considera adequado aos seus fins. Independentemente do uso de um manual ou de material didático propriamente criado, é o professor que desempenha o papel principal no processo de ensino/aprendizagem, e, portanto é imprescindível que no tratamento de conteúdos, este esteja ciente da enorme responsabilidade que assume para com os alunos, particularmente no que diz respeito a escolher temas, fornecer informações e manifestar opiniões. O material didático é um meio para alcançar o objetivo, mas crucial 
HENDRICH, Yvonne: Brito, Cláudia - "Será que somos assim... Para lá da tarefa: implicar os estudantes na aprendizagem de línguas estrangeiras no ensino superior. Porto: FLUP, 2019, pp. 184-207 DOI: https://doi.org/10.21747/9789898969217/paraa10

para o input em termos de conteúdo temático no ponto de vista dos alunos, é sem dúvida alguma, a transmissão das informações pelo professor.

Neste contexto, o próprio professor, ao qual os alunos concedem credibilidade, deveria exigir de si mesmo uma constante atualização, sempre de modo crítico e, sobretudo, disponibilidade para aprender.

\section{Referências}

Araújo, M. T. (2010). Os Manuais de Português Língua Estrangeira em França - um contributo (Mestrado em Língua e Cultura Portuguesa (Português Língua Estrangeira/Língua Segunda). Universidade de Lisboa, Faculdade de Letras, Lisboa. http://repositorio.ul.pt/bitstream/10451/2227/1/ult|078288_tm.pdf.

Bizarro, R. (2002). Língua e cultura no ensino do PLE/PLS, reflexões e exemplos. in: LINGVARVM ARENA, 3, 117-131.http://ler.letras.up.pt/uploads/ficheiros/10953.pdf.

Byram, M., Gribkova, B. \& Starkey, H. (2002). Developing the Intercultural Dimension in Language Teaching. A Practical Guidebook for Teachers. Language Policy Division. Directorate of School, Out-of-School and Higher Education (DGIV), Council of Europe, Strasbourg. http://www.coe.int/t/dg4/linguistic/source/guide_dimintercult_en.pdf

Conselho da Europa (2001). Quadro Europeu Comum de Referência para as Línguas: Aprendizagem, ensino, avaliação, Direcção de José Matias Alves. Tradução: Maria Joana Pimentel do Rosário, Nuno Verdial Soares.Lisboa, Edições ASA (para a edição portuguesa). http://area.dge.mec.pt/gramatica/Quadro_Europeu_total.pdf.

Cook, V.J. (2002). Background to the L2 User.In V.J.Cook (Ed.), Portraits of the L2 User. Second Language Acquisition (pp.1-28). Clevedon: Multilingual Matters.

Decreto-Lei n. 369/90. Diário da República n. 273/1990, Série I de 1990-11-26 (pp. 4835 - 4838), Ministério da Educação. https://dre.pt/pesquisa//search/564668/details/maximized.

Grosso, M. (2006). O perfil do professor de Português para falantes de outras línguas numa sociedade multicultural. In R. Bizarro \& F. Braga (Orgs.), Formação de Professores de Línguas Estrangeiras: reflexões, estudos e experiências (pp. 262-266). Porto: Porto Editora.

Guerreiro, G. F. (2012). Acção Didáctica e Competência Comunicativa em Manuais de Português Língua Estrangeira (Dissertação de Mestrado em Ensino do Português como Língua Segunda e Estrangeira). Universidade Nova de Lisboa, Faculdade de Ciências Sociais e Humanas, Lisboa. http://hdl.handle.net/10362/7373. 
HENDRICH, Yvonne: Brito, Cláudia - "Será que somos assim... Para lá da tarefa: implicar os estudantes na aprendizagem de línguas estrangeiras no ensino superior. Porto: FLUP, 2019, pp. 184-207 DOI: https://doi.org/10.21747/9789898969217/paraa10

Hendrich, Y. \& Brito, C. (2018). Sol, sardinhas e saudade: questões culturais e estereótipos no ensino de português línguas estrangeira. In M. Ellison, M. Pazos Anido, P. Nicólas Martínez \& S. Valente Rodrigues (Orgs), As Línguas Estrangeiras no Ensino Superior: Propostas Didáticas e Casos em Estudo (pp. 277-298). Porto: Faculdade de Letras da Universidade do Porto e APROLÍNGUAS - Associação Portuguesa de Professores de Línguas Estrangeiras no Ensino Superior.

Manuais escolares adotados - Alemanha (2018/2019). Instituto Camões - Instituto da Cooperação e da Língua. https://www.instituto-camoes.pt/activity/o-quefazemos/aprender-portugues/presencial/no-ensino-basico-e-secundario/manuaisescolares.

Oliveira, C. \& Coelho, L. (2014). Aprender Português 3. Português para estrangeiros

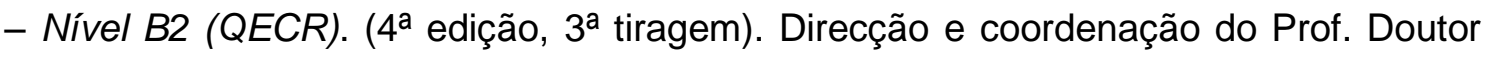
João Malaca Casteleiro.Lisboa: Texto Editores.

Oliveira, C. \& Coelho, L. (2016). Aprender Português 2. Português para estrangeiros

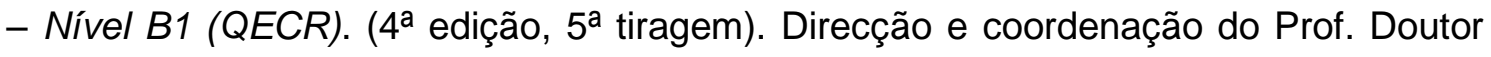
João Malaca Casteleiro.Lisboa: Texto Editores.

Oliveira, C., Coelho, L. \& Ballmann, M. J. (2016). Aprender Português 1. Português para estrangeiros - Níveis A1/A2 (QECR). (1 a edição, 7ª tiragem). Direcção e coordenação do Prof. Doutor João Malaca Casteleiro. Lisboa: Texto Editores.

Tavares, A. (2017). Português XXI, 1. Livro do Aluno. Nível A1 (QECR). (Nova edição, reimpressão). Lisboa: Lidel.

Tavares, A. (2017). Português XXI, 2. Livro do Aluno. Nível A2 (QECR). (Nova edição, reimpressão). Lisboa: Lidel.

Tavares, A. (2017). Português XXI, 3. Livro do Aluno. Nível B1 (QECR). (Nova edição, reimpressão). Lisboa: Lidel. 
HENDRICH, Yvonne: Brito, Cláudia - "Será que somos assim... Para lá da tarefa: implicar os estudantes na aprendizagem de línguas estrangeiras no ensino superior.

\section{Apêndice A}

Professoras: Dr. a Yvonne Hendrich (Mainz) e Cláudia Brito (Frankfurt)

Universidades: Johannes Gutenberg-Universität Mainz e Goethe-Universität Frankfurt/Main

Junho de 2018

\section{Questionário}

Os dados recolhidos pelo presente inquérito serão tratados de forma anónima e analisados no âmbito de um estudo académico que será apresentado no colóquio Aprolínguas 2018 (20-22 de setembro), na Faculdade de Letras da Universidade do Porto.

Informação sobre o / a estudante

Sexo: $m \square \quad f \square \quad$ Idade:

Área de estudos:

1. Se tivesse de escolher o momento mais importante da História de Portugal, qual seria? Justifique a sua escolha.

- A Fundação do Reino de Portugal (século XII)

- Os Descobrimentos (séculos XV e XVI)

- A Restauração da Independência (1640)

- A Implantação da República (1910)

- O 25 de Abril/ a "Revolução dos Cravos" (1974)

- A adesão de Portugal à CEE (1986)

- Outro. Qual?

- Não conheço a história de Portugal.

2. Assinale os adjetivos que, na sua opinião, qualificam os portugueses.

$\begin{array}{ll}\text { preguiçosos } & \text { tristes } \\ \text { trabalhadores } & \text { simples } \\ \text { simpáticos } & \text { extravagantes } \\ \text { antipáticos } & \text { calmos } \\ \text { inteligentes } & \text { nervosos } \\ \text { pouco inteligentes } & \text { frios }\end{array}$


HENDRICH, Yvonne: Brito, Cláudia - "Será que somos assim... Para lá da tarefa: implicar os estudantes na aprendizagem de línguas estrangeiras no ensino superior.

Porto: FLUP, 2019, pp. 184-207 DOI: https://doi.org/10.21747/9789898969217/paraa10

rápidos emocionais

lentos pacientes

alegres impacientes

\author{
Outros(s) qual (quais)? \\ Nenhum. Porquê?
}

\title{
3. Que símbolos relaciona com Portugal? Indique alguns.
}

\section{O que pensa sobre os textos apresentados? Considera que estes correspondem à realidade ou são estereotipados? Justifique.}

1) «Portugal, país com uma história feita de heróis, deu ao mundo novos mundos e, apesar de hoje em dia ser geograficamente menor do que era no passado, continua a ser o responsável pela grande influência que teve noutras terras, culturas e gentes. Durante a nossa viagem pela História, deixámos importantes raízes na Índia (Goa, Damão e Diu), em Timor, em África e no Brasil. Para conhecer Portugal, é preciso que você conheça o seu presente, mas também o seu passado. Conhecer Portugal é conhecer a alma do seu povo, as suas tradicões, as suas festas, os seus usos e costumes. Conhecer Portugal é conhecer as pessoas que tornaram o país conhecido pelo mundo fora. Devido ao seu espírito aberto, os portugueses gostamque os estrangeiros visitem o seu país, conheçam a sua cultura, provem a sua comida. Se você conhece Portugal, ou se já o visitou, então sabe que os portugueses estão sempre prontos para ajudar um visitante em dificuldades. Os portugueses são amigos do seu amigo e esperam que os demais tenham o mesmo sentimento para com eles. Não é à toa que se diz "quem meu filho beija, minha boca adoça». Se você gostar do nosso «Portugalinho», então cairá nas boas graças dos portugueses. E, como «amigo verdadeiro vale mais do que o dinheiro», terá para sempre amigos fiéis e dedicados que the pregarão dois beijinhos e muitos abraços como qualquer bom português.» 
HENDRICH, Yvonne: Brito, Cláudia - "Será que somos assim... Para lá da tarefa: implicar os estudantes na aprendizagem de línguas estrangeiras no ensino superior. Porto: FLUP, 2019, pp. 184-207 DOI: https://doi.org/10.21747/9789898969217/paraa10

2) «Caso os leitores decidam visitar Portugal, ficarão abismados com a simpatia do seu povo. Antes de chegar a Portugal, muitos estrangeiros imaginam que os portugueses são parecidos com os seus irmãos espanhóis, ou talvez com os seus primos italianos. Todos imaginam que os portugueses são vivos, alegres, exuberantes como os seus vizinhos latinos, mas, na realidade, os portugueses são mais calmos. Se decidir conviver com os portugueses, aprenda a ser como eles.»

II

1. Já viajou para Portugal?

Não

Sim. $\square \quad$ Quando? Quantas vezes?

2. O primeiro contacto que teve com Portugal foi a partir das aulas de português?

Não

Sim. $\square \quad$ Como e quando foi?

3. Tem amigos portugueses?

Não

Sim.

3.1. Se, sim. Mantém contacto regular com eles?

Não

Sim. $\square \quad$ Como?

4. Já utilizou algum manual (Lehrbuch) de língua portuguesa?

Não

Sim. $\square \quad$ Qual / Quais?

4.1. Os manuais que referiu foram materiais utilizados em aulas de português?

Não

Sim. $\square \quad$ Em que contexto utilizou estes manuais?

4.2. Na sua opinião, os manuais que conhece abordam suficientemente temas de cultura portuguesa? 
HENDRICH, Yvonne: Brito, Cláudia - "Será que somos assim... Para lá da tarefa: implicar os estudantes na aprendizagem de línguas estrangeiras no ensino superior.

Não

Sim.

5. Considera que os temas de cultura são suficientemente abordados nos cursos de língua portuguesa?

Não

Sim.

6. Na sua opinião, é importante conhecer a cultura e a história de um país para aprender a respetiva língua?

Não

Sim. $\square \quad$ Justifique.

7. Considera que a informação que tem sobre Portugal corresponde à realidade ou é estereotipada? Justifique.

8. Acha positivo e necessário fazer estereótipos culturais?

Não

Sim. $\square \quad$ Justifique. 